\title{
The use of cIMT as a predictor of postoperative stroke in patients undergoing surgical repair of acute type a aortic dissection
}

Kai Zhang ${ }^{1+}$, Si-Chong Qian ${ }^{1+}$, Xu-Dong Pan ${ }^{1}$, Song-Bo Dong ${ }^{1}$, Jun Zheng ${ }^{1}$, Hong Liư ${ }^{2}$, Yue-Li Wang ${ }^{3}$ and Li-Zhong Sun ${ }^{1 *}$

\begin{abstract}
Background: Acute type A aortic dissection (ATAAD) is a life-threatening condition that requires surgical intervention. Stroke remains an extremely serious adverse outcome that can occur in ATAAD patients undergoing aortic arch repair, leading to higher rates of patient mortality and decreased postoperative quality of life. In the present study, we sought to determine whether carotid intima-media thickness (CIMT) is a reliable predictor of postoperative stroke risk.

Materials and methods: This was a prospective study of 76 patients with ATAAD undergoing aortic arch repair. For all patients, CIMT was determined preoperatively through a Doppler-based method. Incidence of different forms of neurological dysfunction, including temporary neurological dysfunction (TND) and stroke, was monitored in these patients, and the relationship between CIMT and stroke incidence was assessed using a receiver-operating characteristic (ROC) curve. Prognostic variables associated with stroke risk were further identified through univariate and multivariate analyses.
\end{abstract}

Results: A total of 26/76 (34.2\%) patients in the present study suffered from neurological dysfunction, of whom 16 (21.0\%) suffered from TND and 10 (13.2\%) suffered a stroke. The remaining 50 patients (65.8\%) did not suffer from neurological dysfunction. The CIMT values in the stroke, TND, and neurological dysfunction-free patients in this study were $1.12 \pm 0.19(\mathrm{~mm}), 0.99 \pm 0.13(\mathrm{~mm})$, and $0.87 \pm 0.13(\mathrm{~mm})$, respectively. A total of 4 patients in this cohort died during the study, including 1 in the TND group and 3 in the stroke group. An ROC curve analysis indicated that cIMT could predict stroke with an area under the curve value of $0.844(95 \% \mathrm{Cl}, 0.719-0.969 ; p<0.001)$. A multivariate analysis revealed that cIMT $>0.9 \mathrm{~mm}$ was independently associated with stroke risk $(p=0.018)$.

Conclusion: We found that CIMT can be used to predict postoperative stroke risk in ATAAD patients undergoing aortic arch repair, with a cIMT $>0.9 \mathrm{~mm}$ coinciding with increased stroke risk in these patients.

(Continued on next page)

\footnotetext{
* Correspondence: Lizhongsun@foxmail.com

${ }^{\dagger}$ Kai Zhang and Si-Chong Qian contributed equally to this work.

'Department of Cardiovascular Surgery, Beijing Anzhen Hospital, Capital

Medical University, Beijing Institute of Heart, Lung and Blood Vessel Diseases,

2 Anzhen Rd, Beijing 100029, China

Full list of author information is available at the end of the article
}

C C The Author(s). 2020 Open Access This article is licensed under a Creative Commons Attribution 4.0 International License, which permits use, sharing, adaptation, distribution and reproduction in any medium or format, as long as you give appropriate credit to the original author(s) and the source, provide a link to the Creative Commons licence, and indicate if changes were made. The images or other third party material in this article are included in the article's Creative Commons licence, unless indicated otherwise in a credit line to the material. If material is not included in the article's Creative Commons licence and your intended use is not permitted by statutory regulation or exceeds the permitted use, you will need to obtain permission directly from the copyright holder. To view a copy of this licence, visit http://creativecommons.org/licenses/by/4.0/ The Creative Commons Public Domain Dedication waiver (http://creativecommons.org/publicdomain/zero/1.0/) applies to the data made available in this article, unless otherwise stated in a credit line to the data. 
(Continued from previous page)

Trial registration: ChiCTR1900022289. Date of registration 4 April 2019 retrospectively registered.

Keywords: Carotid intima-media thickness (cIMT), Type A aortic dissection, Stroke, Risk factor

\section{Introduction}

Acute type A aortic dissection (ATAAD) is a particularly deadly condition, with extremely high rates of intraoperative morbidity and mortality. Surgical treatment of ATAAD patients is primarily focused on saving the lives of these individuals. While associated surgical approaches have improved substantially in recent years, aortic arch repair in ATAAD patients remains a complex procedure with significant associated risk.

A number of technical improvements to aortic arch repair procedures have been described in recent years [1-4], including the use of hypothermic circulatory arrest as a means of improving cerebral protection and the use of selective cerebral perfusion as a mains of safely extending arrest duration. Even with these improvements, however, postoperative stroke remains an extremely serious complication of aortic arch repair surgery that can result in high rates of patient mortality and a significant reduction in postoperative patient quality of life [5-7].

A number of studies in recent years have examined carotid intima-media thickness (cIMT) as a predictor for the risk of cerebral and cardiovascular events in patients [8-10]. Whether cIMT can similarly be used to predict the risk of postoperative stroke in ATAAD patients undergoing aortic arch repair, however, remains to be definitely determined. To that end, in the present study we sought to assess the prognostic relevance of preoperative cIMT as a predictor of postoperative stroke incidence in ATAAD patients undergoing aortic arch surgery.

\section{Materials and methods}

The Ethics Committee of Beijing Anzhen Hospital approved this study. This study was registered in the Chinese Clinical Trials Registry (www.chictr.org.cn, ChiCTR1 900022289).

\section{Patients}

This prospective observational study was conducted between December 2016 and June 2017. Patients enrolled in the present study were those ATAAD patients who were at least 18 years of age and who were undergoing total arch replacement (TAR) with frozen elephant trunk (FET) implantation. Exclusion criteria included a history of stroke, aortic surgery, pregnancy, or death during the operation. Patients with coma, altered consciousness, or speech slurring before operations were also excluded. During surgery, both moderate hypothermic circulatory arrest (MHCA) and antegrade selective cerebral perfusion (SCP) were employed in all patients.

In total, 80 ATAAD patients that underwent TAR with FET were eligible for study enrollment, of whom 4 were excluded due to intraoperative death. The remaining 76 ATAAD patients were enrolled in this study. All operations were performed randomly by four surgery teams. A flow chart of the screening and registration of study participants was given in Fig. 1.

\section{cIMT measurement}

A standard ultrasound procedure with a $9-\mathrm{MHz}$ transducer (GE Vivid E9, Horten, Norway) was used conducted by two highly-experienced sonographers in order to obtain images of the cIMT. Inter-observer variability was determined by the measurement of cIMT three times by each investigator in 10 healthy volunteer participants $(p=0.672)$.

A certified reader examined each image, manually drawing a continuous line at the cIMT interface in these images after which cIMT values were determined. The right and left cIMT measurements over a $1 \mathrm{~cm}$ segment of the carotid artery $\sim 0.5 \mathrm{~cm}$ below the carotid artery bulb not containing any plaques (cIMT $\geq 1.9 \mathrm{~mm}$ ) were averaged together to determine cIMT values.

\section{Definitions}

Stroke and temporary neurological dysfunction (TND) were both classified as forms of neurological dysfunction in the present study. Stroke was defined as the development of any several global or focal neurological deficits including altered consciousness or speech slurring as a result of hemorrhagic or ischemic events. Stroke was confirmed using computed tomography (CT) imaging. TND was diagnosed based on the presence of prolonged postoperative confusion, motor weakness, seizures, agitation, or delirium. In TND patients, CT findings were typically normal.

\section{Surgical technique}

All operations were performed through median sternotomy. Briefly, this procedure was performed using right axillary artery cannulation for cardiopulmonary bypass $(\mathrm{CPB})$ and SCP [5-10 $\mathrm{mL} /(\mathrm{kg} \cdot \mathrm{min})]$ under MHCA. Associated operations, such as mitral valve and aortic root replacement, were performed during cooling. The 


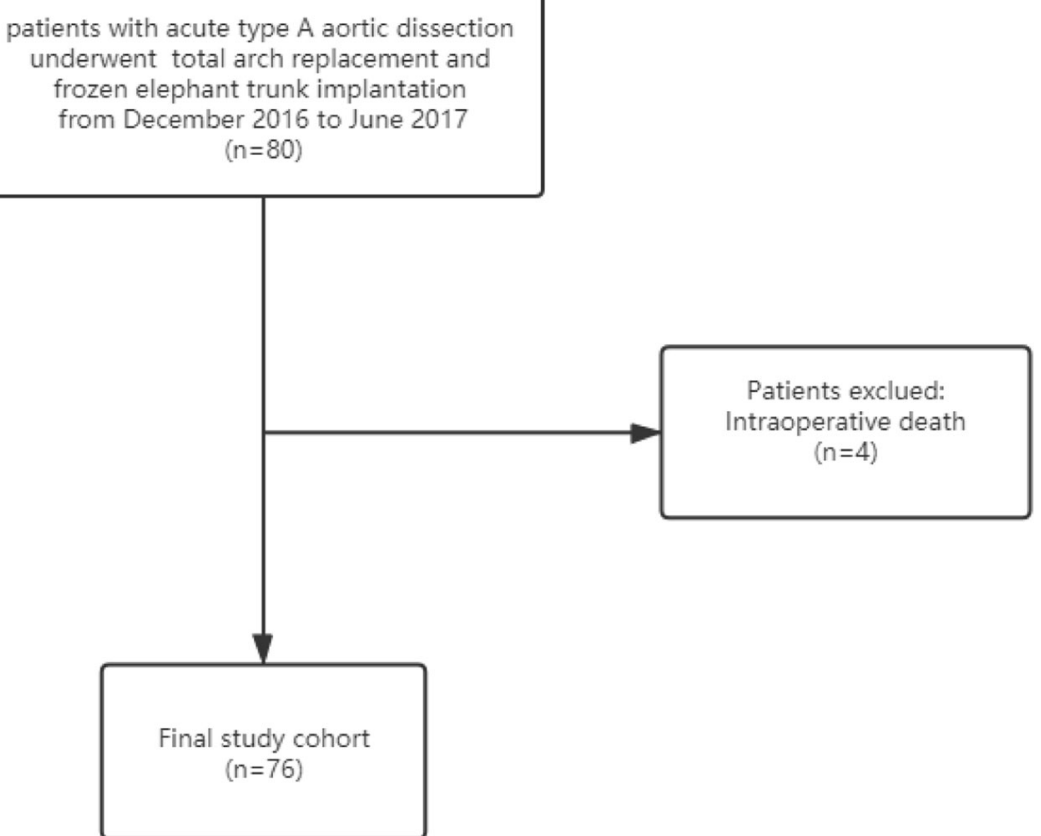

Fig. 1 Flow chart diagram

TAR with FET surgical technique has been previously described $[2,11]$. The procedure involved the implantation of a FET (MicroPort Medical Company Limited, Shanghai, China) in the descending aorta, followed by TAR with a four-branched prosthetic graft (Maquet Cardiovascular, Wayne, NJ). Distal reperfusion was initiated upon the completion of descending aortic anastomosis. The left carotid artery was initially reconstructed to achieve bilateral perfusion, the ascending aorta was then treated to prevent coronary ischaemia, and the innominate and subclavian arteries were treated last.

\section{Statistical analysis}

Continuous and categorical data were given as mean \pm standard deviation (SD) or percentage, and were compared via t-tests or Kruskal-Wallis tests and chi-squared tests or Fisher's exact tests, respectively. Logistic regression analyses were used to identify variables associated with postoperative stroke risk, with a multivariate analysis used to assess the link between patient stroke risk cIMT $>0.9 \mathrm{~mm}$ [12]. Covariates were adjusted based upon previous reports [13]. Briefly, when the addition of a variable resulted in a change in the odds ratio of $\geq 10 \%$, adjustments were made. Covariates in this model included male, body mass index (BMI), preoperative white blood cell count, coronary artery involvement, circulatory arrest time, hydropericardium, and Marfan syndrome. This cIMT cutoff value used to predict postoperative stroke risk was determined based upon a receiver-operating characteristic (ROC) curve. Youden's index ( $\mathrm{J}=$ Sensitivity + Specificity -1$)$ was used to determine the optimal cIMT cut-off value for this curve. All tests were 2 -sided, with $p<0.05$ as the significance threshold. R and Empower Stats (http://www.empowerstats.com, X\&Y Solutions, Inc., MA, USA) was used for all statistical testing.

\section{Results}

A total of 76 patients were included in this analysis, of whom 50 did not suffer from any neurological dysfunction (65.8\%), 16 suffered from TND (21.1\%), and 10 suffered from stroke (13.2\%). Table 1 shows both the baseline and operative characteristics for these patients. Patients in the stroke, TND, and neurological dysfunction-free (NDF) groups exhibited cIMT values of $1.12 \pm 0.19(\mathrm{~mm}), 0.99 \pm 0.13(\mathrm{~mm})$, and $0.87 \pm 0.13$ $(\mathrm{mm})$, respectively $(p<0.001)$. Just $15 / 50 \quad(30.0 \%)$ of patients in the NDF group exhibited a cIMT value > $0.9 \mathrm{~mm}$, whereas $12 / 16(75.0 \%)$ and $8 / 10$ (80\%) patients in the TND and stroke groups, respectively, had a cIMT value $>0.9 \mathrm{~mm}(p<0.001)$. All other measured variables were comparable among these three patient groups.

\section{Operative morbidity and mortality}

Table 2 showed the postoperative complications of these patients. Overall patient mortality in the present study was $5.3 \%$ ( 4 of 76 ), with all deceased patients having suffered from some form of neurological dysfunction (1 TND, 3 stroke) $(p<0.01)$. A total of 8 
Table 1 Demographic characteristics, preoperative and intraoperative data of patients

\begin{tabular}{|c|c|c|c|c|c|}
\hline Variable & $\begin{array}{l}\text { Total } \\
(\boldsymbol{n}=76)\end{array}$ & $\begin{array}{l}\text { NDF } \\
(\boldsymbol{n}=50)\end{array}$ & $\begin{array}{l}\text { TND } \\
(\boldsymbol{n}=16)\end{array}$ & $\begin{array}{l}\text { Stroke } \\
(\boldsymbol{n}=10)\end{array}$ & $\boldsymbol{P}$ value \\
\hline Male & $61(80.3)$ & $40(80.0)$ & $15(97.8)$ & $6(60.0)$ & 0.109 \\
\hline Age (year) & $45.8 \pm 9.9$ & $45.3 \pm 10.6$ & $48.1 \pm 9.0$ & $47.0 \pm 8.4$ & 0.799 \\
\hline BMI $\left(\mathrm{kg} / \mathrm{m}^{2}\right)$ & $27.4 \pm 4.6$ & $27.4 \pm 4.2$ & $27.8 \pm 5.8$ & $26.8 \pm 4.9$ & 0.863 \\
\hline Hypertension & $60(78.9)$ & $41(82.0)$ & $12(75.0)$ & $7(70.0)$ & 0.634 \\
\hline Diabetes mellitus & $3(3.9)$ & $3(6.0)$ & 0 & 0 & 0.444 \\
\hline Marfan syndrome & $1(1.3)$ & 0 & $1(6.3)$ & 0 & 0.150 \\
\hline Smoking history & $33(43.4)$ & $21(42.0)$ & $9(56.3)$ & $3(30.0)$ & 0.397 \\
\hline LVEF (\%) & $62.2 \pm 4.9$ & $62.3 \pm 4.5$ & $60.7 \pm 6.5$ & $63.9 \pm 3.6$ & 0.258 \\
\hline White blood cell count $\left(10^{9} / \mathrm{l}\right)$ & $12.0 \pm 3.0$ & $11.5 \pm 3.0$ & $12.99 \pm 3.6$ & $12.8 \pm 1.8$ & 0.155 \\
\hline Serum creatinine (umol/l) & $84.7 \pm 31.6$ & $78.1 \pm 20.4$ & $105.9 \pm 51.6$ & $84.4 \pm 24.3$ & 0.142 \\
\hline \multicolumn{6}{|l|}{ Primary entry tear } \\
\hline Unknown & $14(18.4)$ & $7(14.0)$ & $4(25.0)$ & $3(30.0)$ & 0.367 \\
\hline Ascending aorta & $57(75.0)$ & $38(76.0)$ & $12(75.0)$ & $7(70.0)$ & 0.923 \\
\hline Aortic arch & $5(6.6)$ & $5(10.0)$ & 0 & 0 & 0.993 \\
\hline Coronary artery involvement & $20(26.3)$ & $17(34.0)$ & $1(6.3)$ & $2(20.0)$ & 0.628 \\
\hline Aortic root repair & & & & & 0.606 \\
\hline Ascending aorta replacement & $50(65.8)$ & $31(62.0)$ & $12(75.0)$ & $7(70.0)$ & \\
\hline Bentall procedure & $26(34.2)$ & $19(38.0)$ & $4(25.0)$ & $3(30.0)$ & \\
\hline Lowest nasopharyngeal temperature $\left({ }^{\circ} \mathrm{C}\right)$ & $23.5 \pm 0.8$ & $23.5 \pm 0.8$ & $23.7 \pm 0.7$ & $23.7 \pm 0.5$ & 0.412 \\
\hline CPB time (min) & $205.8 \pm 43.2$ & $199.5 \pm 41.6$ & $223.9 \pm 45.3$ & $207.8 \pm 43.6$ & 0.143 \\
\hline Cross-clamp time (min) & $114.2 \pm 30.5$ & $109.9 \pm 30.5$ & $129.5 \pm 29.8$ & $111.0 \pm 26.5$ & 0.724 \\
\hline Circulatory arrest time (min) & $22.9 \pm 7.5$ & $22.0 \pm 7.5$ & $26.4 \pm 7.6$ & $22.2 \pm 6.1$ & 0.737 \\
\hline Intraoperative transfusion of PRBCs & $44(57.9)$ & $27(54.0)$ & $12(75.0)$ & $5(50.0)$ & 0.589 \\
\hline Intraoperative transfusion of FFP & $38(50.0)$ & $24(48.0)$ & $10(62.5)$ & $4(40.0)$ & 0.500 \\
\hline Intraoperative transfusion of platelets & $5(6.9)$ & $3(6.0)$ & $2(12.5)$ & 0 & 0.993 \\
\hline cIMT (mm) & $0.93 \pm 0.16$ & $0.87 \pm 0.13$ & $0.99 \pm 0.13$ & $1.12 \pm 0.19$ & $<0.001$ \\
\hline $\operatorname{cIMT}(\mathrm{mm})>0.9$ & $35(46.5)$ & $15(30.0)$ & $12(75.0)$ & $8(80.0)$ & $<0.001$ \\
\hline
\end{tabular}

Continuous data are presented as the mean \pm standard deviation and categorical data as number (percentage)

Abbreviations: NDF neurological dysfunction-free, TND temporary neurological dysfunction, $B M I$ body mass index, $L V E F$ left ventricular ejection fraction, CABG coronary artery bypass grafting, CPB cardiopulmonary bypass, PRBCs packed red blood cells, FFP fresh-frozen plasma, cIMT carotid intima-media thickness

Table 2 Postoperative complications of patients

\begin{tabular}{|c|c|c|c|c|c|}
\hline Variable & $\begin{array}{l}\text { Total } \\
(\boldsymbol{n}=76)\end{array}$ & $\begin{array}{l}\text { NDF } \\
(\boldsymbol{n}=50)\end{array}$ & $\begin{array}{l}\text { TND } \\
(\boldsymbol{n}=16)\end{array}$ & $\begin{array}{l}\text { Stroke } \\
(\boldsymbol{n}=10)\end{array}$ & $\boldsymbol{P}$ value \\
\hline Paraplegia & $7(9.2)$ & $4(8.0)$ & $1(6.3)$ & $2(20.0)$ & 0.439 \\
\hline Continuous renal replacement therapy & $8(10.5)$ & 0 & $5(31.3)$ & $3(30.0)$ & $<0.001$ \\
\hline Tracheal reintubation & $8(10.5)$ & $1(2.0)$ & $4(25.0)$ & $3(30.0)$ & 0.003 \\
\hline Tracheotomy & $5(6.6)$ & $1(2.0)$ & $2(12.5)$ & $2(20.0)$ & 0.037 \\
\hline Reexploration for bleeding & $5(6.6)$ & $1(2.0)$ & $2(12.5)$ & $2(20.0)$ & 0.037 \\
\hline Mortality & $4(5.3)$ & 0 & $1(6.3)$ & $3(30.0)$ & $<0.001$ \\
\hline
\end{tabular}

Continuous data are presented as the mean \pm standard deviation and categorical data as number (percentage) Abbreviations: NDF neurological dysfunction-free, TND temporary neurological dysfunction 
patients $(10.5 \%)$ underwent postoperative continuous renal replacement therapy, including 3 in the TND group, and 5 in the stroke group $(p<0.01)$. Patients that suffered from postoperative neurological dysfunction also had higher rates of tracheal reintubation (3/ $10,30.0 \%$; $4 / 16,25.0 \%$; vs $1 / 50,2.0 \% ; p=0.003)$. A total of $2(20.0 \%), 1(6.3 \%)$, and $4(8.0 \%, p=0.439)$ patients in the stroke, TND, and NDF groups suffered from postoperative paraplegia. Patients that suffered from stroke or TND also had higher rates of requiring tracheotomy $(20 \%$ and $12.5 \%$, respectively, vs $2 \%$; $p=0.037)$ and reexploration for bleeding $(20 \%$ and $12.5 \%$, respectively vs $2 \% ; p=0.037$ ).

\section{Univariate and multivariate analysis}

A univariate analysis revealed that of the tested variables, only cIMT $>0.9 \mathrm{~mm}$ was associated with increased stroke incidence (OR, 5.78; 95\% CI, 1.1429.35; $p=0.034$; Table 3). A multivariate analysis was then performed to confirm this finding, incorporating covariates including male, BMI, preoperative white blood cell count, coronary artery involvement, circulatory arrest time, hydropericardium, and Marfan syndrome (Table 4). Following adjustment for these covariates, cIMT $>0.9 \mathrm{~mm}$ was still associated with increased stroke risk (OR 5.78, 95\% CI 1.14-29.35; $p=0.018)$.

Table 3 Univariate analysis of risk factors associated with stroke

\begin{tabular}{|c|c|c|c|c|}
\hline Variables & $\begin{array}{l}\text { No-stroke } \\
(\boldsymbol{n}=66)\end{array}$ & $\begin{array}{l}\text { Stroke } \\
(\boldsymbol{n}=10)\end{array}$ & $\mathrm{OR}(95 \% \mathrm{Cl})$ & $\boldsymbol{P}$ value \\
\hline Male & $55(83.3)$ & $6(60.0)$ & $0.30(0.07-1.24)$ & 0.097 \\
\hline Age (year) & $45.6 \pm 10.2$ & $47.0 \pm 8.4$ & $1.01(0.95-1.09)$ & 0.684 \\
\hline $\mathrm{BMI}\left(\mathrm{kg} / \mathrm{m}^{2}\right)$ & $27.5 \pm 4.6$ & $26.8 \pm 4.9$ & $0.96(0.82-1.13)$ & 0.638 \\
\hline Hypertension & $53(80.3)$ & $7(70.0)$ & $0.57(0.13-2.52)$ & 0.461 \\
\hline Diabetes mellitus & $3(4.5)$ & 0 & a & 0.995 \\
\hline Hyperlipidemia & $5(7.6)$ & $1(10.0)$ & $1.36(0.14-12.97)$ & 0.792 \\
\hline Marfan syndrome & $1(1.5)$ & 0 & a & 0.995 \\
\hline Smoking history & $30(45.5)$ & $3(30.0)$ & $0.51(0.12-2.16)$ & 0.364 \\
\hline Hydropericardium & $11(16.7)$ & $2(20.0)$ & $1.25(0.23-6.70)$ & 0.795 \\
\hline LVEF (\%) & $61.9 \pm 5.1$ & $63.9 \pm 3.6$ & $1.09(0.94-1.26)$ & 0.241 \\
\hline White blood cell count $\left(10^{9} / 1\right)$ & $11.9 \pm 3.2$ & $12.8 \pm 1.8$ & $1.11(0.89-1.38)$ & 0.346 \\
\hline Serum creatinine (umol/l) & $84.7 \pm 32.7$ & $84.4 \pm 24.3$ & $1.00(0.98-1.02)$ & 0.973 \\
\hline \multicolumn{5}{|l|}{ Primary entry tear } \\
\hline Unknown & $11(16.7)$ & $3(30.0)$ & 1.0 & \\
\hline Ascending aorta & $50(75.8)$ & $7(70.0)$ & $0.51(0.11-2.30)$ & 0.384 \\
\hline Aortic arch & $5(7.6)$ & 0 & a & 0.993 \\
\hline Coronary artery involvement & $18(27.3)$ & $2(20.0)$ & $0.67(0.13-3.44)$ & 0.628 \\
\hline \multicolumn{5}{|l|}{ Aortic root repair } \\
\hline Ascending aorta replacement & $43(65.2)$ & $7(70.0)$ & 1.0 & \\
\hline Bentall procedure & $23(34.9)$ & $3(30.0)$ & $1.09(0.53-2.24)$ & 0.806 \\
\hline Lowest nasopharyngeal temperature $\left({ }^{\circ} \mathrm{C}\right)$ & $23.5 \pm 0.8$ & $23.7 \pm 0.5$ & $1.47(0.61-3.56)$ & 0.394 \\
\hline CPB time (min) & $205.4 \pm 43.5$ & $207.8 \pm 43.6$ & $1.00(0.99-1.02)$ & 0.871 \\
\hline Cross-clamp time (min) & $114.6 \pm 31.3$ & $111.0 \pm 26.5$ & $1.00(0.97-1.02)$ & 0.724 \\
\hline Circulatory arrest time (min) & $23.1 \pm 7.7$ & $22.2 \pm 6.1$ & $0.98(0.89-1.08)$ & 0.737 \\
\hline Intraoperative transfusion of PRBCs & $39(59.1)$ & $5(50.0)$ & $0.69(0.18-2.63)$ & 0.589 \\
\hline Intraoperative transfusion of FFP & $34(51.5)$ & $4(40.0)$ & $0.63(0.16-2.43)$ & 0.500 \\
\hline Intraoperative transfusion of platelets & $5(7.6)$ & 0 & a & 0.993 \\
\hline $\operatorname{cIMT}(\mathrm{mm})>0.9$ & $27(40.9)$ & $8(80.0)$ & $5.78(1.14-29.35)$ & 0.034 \\
\hline
\end{tabular}

Continuous data are presented as the mean \pm standard deviation and categorical data as number (percentage)

Abbreviations: OR odd ratio, $95 \% \mathrm{Cl} 95 \%$ confidence interval, $B M I$ body mass index, $L V E F$ left ventricular ejection fraction, CABG coronary artery bypass grafting, CPB cardiopulmonary bypass, PRBCs packed red blood cells, FFP fresh-frozen plasma, CIMT carotid intima-media thickness

${ }^{\text {aT }}$ The result failed because of the small sample size 
Table 4 Multivariable analysis to assess the independent impact of CIMT group on stroke in patients with ATAAD

\begin{tabular}{lllll}
\hline Variable & $\begin{array}{l}\text { Model I } \\
\text { OR }(95 \% \mathrm{Cl})\end{array}$ & P-value & $\begin{array}{l}\text { Model II } \\
\text { OR }(95 \% \mathrm{Cl})\end{array}$ & $P$-value \\
\hline CIMT $(\mathrm{mm})>0.9$ & $5.78(1.14-29.35)$ & 0.034 & $9.53(1.47-61.72)$ & 0.018
\end{tabular}

Abbreviations: CIMT carotid intima-media thickness, ATAAD acute type A aortic dissection, OR odd ratio, $95 \% \mathrm{Cl}$ 95\% confidence interval Model I: unadjusted

Model II: adjusted for male, BMI, Marfan syndrome, hydropericardium, preoperative white blood cell count, coronary artery involvement, circulatory arrest time

\section{Area under the ROC curve analysis}

The area under the ROC curve for cIMT values in the present study was found to be 0.844 (95\% CI, 0.719 $0.969 ; p<0.001$; Fig. 2 ). This analysis confirmed that cIMT offered significant value as a predictor of stroke risk $(p<0.001)$, with sensitivity and specificity values of $90.0 \%$ and $72.7 \%$, respectively. The cIMT cutoff value for diagnosing stroke was 0.627 .

\section{Discussion}

Our study revealed that the noninvasive measurement of cIMT using carotid ultrasonography can predict the risk of postoperative stroke in ATAAD patients undergoing aortic arch repair with high sensitivity and specificity $(90.0 \%$ and $72.7 \%$, respectively). Specifically, we determined that cIMT $>0.9 \mathrm{~mm}$ was independently associated with increased risk of postoperative stroke in these individuals.

While there have been significant improvements in ATAAD patient outcomes following surgical aortic arch repair, the rates of morbidity and mortality associated with the procedure remain high with cerebral complications affecting from $7 \%$ to $35 \%$ of patients $[14,15]$. The most recent international registry of aortic dissection study of ATAAD [16] reported an approximate $10 \%$ rate of cerebral complications, with the latest Society of Thoracic Surgeons Adult Cardiac Surgery Database study [1] reporting a $13 \%$ risk of postoperative stroke following surgical repair of ATAAD (945/7353 patients across 772 centers). These findings were consistent with the results of our smaller scale study (10/76, 13.2\%).

Many recent studies have utilized cIMT as a key predictor of cardiovascular risk [8-10], but to date no studies have focused on this parameter as a predictor of postoperative stroke risk in patients following aortic arch surgery. In the present study, we therefore examined the ability of cIMT to predict such postoperative stroke risk in ATAAD patients given that cIMT has been previously shown in other contexts to independently predict postoperative stroke risk even in light of more traditional predictors of cardiovascular risk [17-20]. Recent

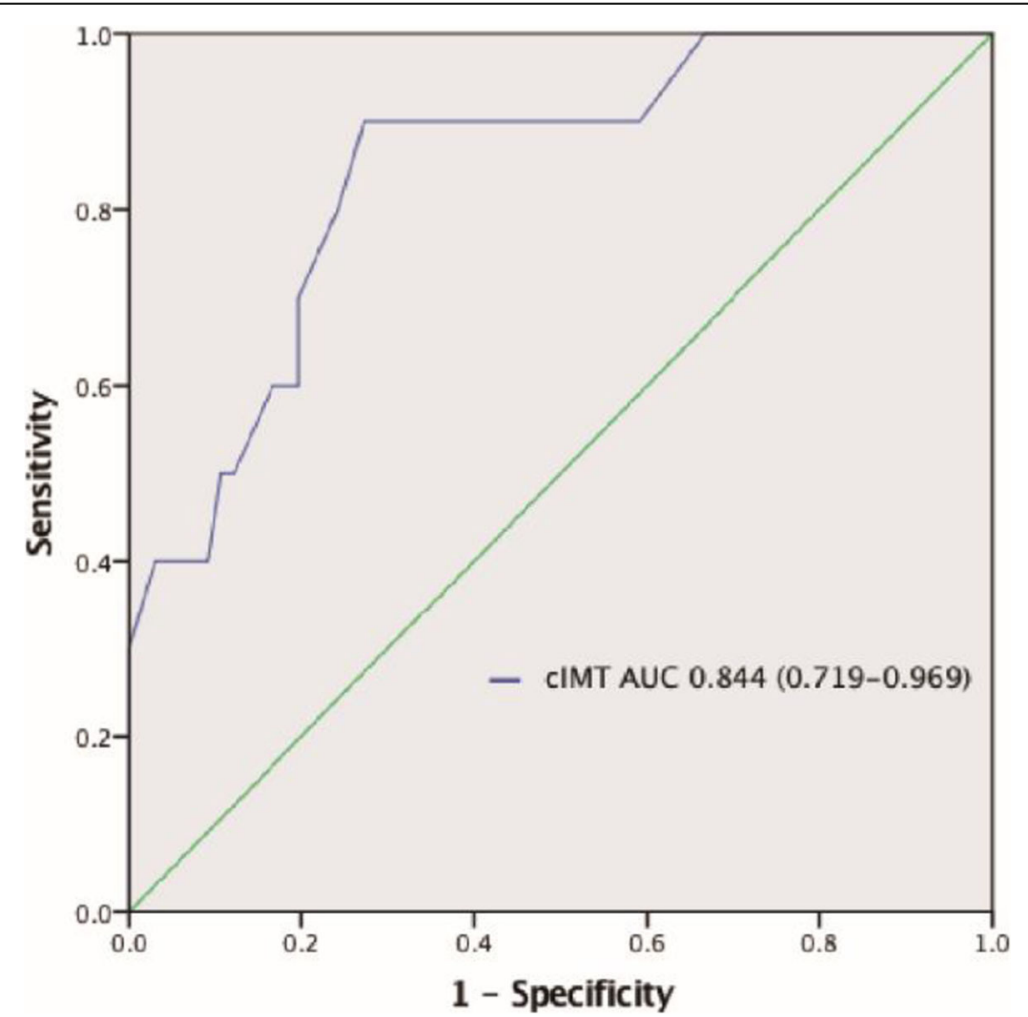

Fig. 2 Receiver-operating characteristic of CIMT before the operation. Abbreviations: AUC, areas under receiver-operating characteristic curve; CIMT, carotid intima-media thickness 
guidelines published by the American College of Cardiology Foundation-American Heart Association guidelines also highlight cIMT as having a level IIa recommendation for cardiovascular risk evaluation [21].

At present the clinical parameters that are associated with postoperative stroke risk following aortic arch repair remain uncertain, although previous studies have found that postoperative stroke are among the primary drivers of operative mortality $[5-7,22]$. Some studies have also found that deep hypothermic circulatory arrest (DHCA) time [23] and history of stroke [24] were all associated with postoperative stroke risk, but other studies have failed to replicate these findings with multivariate analyses suggesting that DHCA time was not predictive of postoperative stroke incidence [24, 25]. In our study, CPB time, cross-clamp time, and circulatory arrest time, all of which are usually deemed to be associated with cerebral ischemia risk, were found not to be significantly associated with stroke incidence in a univariate analysis. We believe there may be three reasons for this finding: First, prolonged operation time is known to lead to higher rates of adverse outcomes, but our experienced surgeons were able to maintain relatively low durations of $\mathrm{CPB}$, cross-clamp, and circulatory arrest in this study. In addition, SCP significantly extended the safe arch intervention time and increased brain tissue tolerance in these patients. Second, when we divided the patients into three groups based on neurological outcomes, it was clear that patients in the TND group experienced longer $\mathrm{CPB}$, cross-clamp, and circulatory arrest durations, which may have resulted in transient ischemia but not substantial brain damage in these patients. Third, this study had a relatively small sample size and thus limited statistical power, and as such these variables were still incorporated into the final multivariate logistic regression analyses in order to ensure that the results are as accurate as possible. In the present study, of analyzed variables only a cIMT value $>0.9 \mathrm{~mm}$ was found to be independently associated with stroke risk. This parameter serves as a valuable index for quantifying vascular abnormalities.

In patients with ATAAD, it is imperative that surgery be conducted as quickly as possible as mortality rates rise in a time-dependent manner, and as such only essential examinations should be performed before surgery is initiated. Owing to its ease of measurement and ability to predict stroke risk, cIMT values thus represent a feasible and potentially valuable tool for stratifying ATAAD patients based upon risk. The ability to determine which patients are at a high-risk of postoperative stroke may have important clinical implications, as more attention can then be paid to these high-risk individuals. When symptoms are evident in these patients, cranial CT examination should be performed immediately, and treatment should be conducted as early as possible to ensure an optimal prognosis.

\section{Study limitations}

This study has a number of limitations. For one, this was a single-center study with a relatively small number of patients. In addition, there is potential for selection bias as we focused specifically on ATAAD patients that underwent TAR with FET, whereas other studies may not have selected patients in this manner leading to differences in study outcomes. Third, We did not have adequate cranial CT to confirm all of our enrolled patients did not suffer from stoke before operation. Fourth, we did not assess long-term morbidity or mortality in patients that suffered from stroke in the present study. Despite these limitations, our data still suggests that cIMT values may be of benefit for detecting stroke risk, thereby offering an opportunity to improve outcomes in ATAAD patients undergoing aortic arch repair.

\section{Conclusions}

Our analyses clearly indicate that cIMT can be used as a reliable predictor of postoperative stroke risk in ATAAD patients scheduled to undergo aortic arch repair. We found a cIMT value $>0.9 \mathrm{~mm}$ to be associated with increased stroke risk in these patients with good specificity and sensitivity.

\section{Acknowledgments \\ The authors would like to thank LEXIS for its linguistic assistance during the preparation of this manuscript.}

\section{Authors' contributions}

(I) Conception and design: S Qian, K Zhang, L Sun; (II) Administrative support: L Sun; (III) Provision of study materials or patients: L Sun; (IV) Collection and assembly of data: S Qian, K Zhang, Y Wang; (V) Data analysis and interpretation: S Qian, K Zhang, H Liu; (VI) Manuscript writing: All authors; (VII) Final approval of manuscript: All authors.

\section{Funding}

This study was supported in part by the National Key Technologies Research and Development Program (No.2015BAl12B03), the Beijing Major Science and Technology Projects from Beijing Municipal Science and Technology Commission (No. Z171100001017083), and the Beijing Municipal Natural Science Foundation (No. 7202038).

\section{Availability of data and materials \\ The datasets used or analyzed during the current study are available from the corresponding author on reasonable request.}

\section{Ethics approval and consent to participate}

The study protocol was approved by the ethics committee at Anzhen Hospital (Institutional Review Board File 2019030X), and all experimental methods were performed in accordance with the relevant guidelines and regulations.

\section{Consent for publication}

Consent was obtained from the patients or their relatives.

Competing interests

The authors have declared that no interest. 


\section{Author details}

'Department of Cardiovascular Surgery, Beijing Anzhen Hospital, Capital Medical University, Beijing Institute of Heart, Lung and Blood Vessel Diseases, 2 Anzhen Rd, Beijing 100029, China. ${ }^{2}$ Department of Cardiothoracic Surgery, Chinese Academy of Medical Sciences \& Peking Union Medical College, Beijing, China. ${ }^{3}$ Department of Echocardiography, Beijing Anzhen Hospital, Capital Medical University, Beijing, China.

\section{Received: 4 January 2020 Accepted: 30 March 2020}

Published online: 15 April 2020

\section{References}

1. Ghoreishi M, Sundt TM, Cameron DE, Holmes SD, Roselli EE, Pasrija C, Gammie JS, Patel HJ, Bavaria JE, Svensson LG, et al. Factors associated with acute stroke after type a aortic dissection repair: an analysis of the Society of Thoracic Surgeons National Adult Cardiac Surgery Database. J Thorac Cardiovasc Surg. 2019. https://doi.org/10.1016/j.jtcvs.2019.06.016. [Epub ahead of print].

2. Sun LZ, Qi RD, Zhu JM, Liu YM, Zheng J. Total arch replacement combined with stented elephant trunk implantation: a new "standard" therapy for type a dissection involving repair of the aortic arch? Circulation. 2011;123(9):971-8.

3. Preventza O, Coselli JS, Garcia A, Kashyap S, Akvan S, Simpson KH, Price MD, Bakaeen FG, Cornwell LD, Omer S, et al. Moderate hypothermia at warmer temperatures is safe in elective proximal and total arch surgery: results in 665 patients. J Thorac Cardiovasc Surg. 2017;153(5):1011-8.

4. Krüger T, Weigang E, Hoffmann I, Blettner M, Aebert H. Cerebral protection during surgery for acute aortic dissection type a: results of the German registry for acute aortic dissection type a (GERAADA). Circulation. 2011; 124(4):434-43.

5. Goossens D, Schepens M, Hamerlijnck R, Hartman M, Suttorp MJ, Koomen E, Vermeulen F. Predictors of hospital mortality in type A aortic dissections: a retrospective analysis of 148 consecutive surgical patients. Cardiovasc Surg (London, England). 1998;6(1):76-80.

6. Immer FF, Lippeck C, Barmettler H, Berdat PA, Eckstein FS, Kipfer B, Saner H, Schmidli J, Carrel TP. Improvement of quality of life after surgery on the thoracic aorta: effect of antegrade cerebral perfusion and short duration of deep hypothermic circulatory arrest. Circulation. 2004;110(11 Suppl 1):I250-5.

7. Reich DL, Uysal S, Sliwinski M, Ergin MA, Kahn RA, Konstadt SN, McCullough J, Hibbard MR, Gordon WA, Griepp RB. Neuropsychologic outcome after deep hypothermic circulatory arrest in adults. J Thorac Cardiovasc Surg. 1999;117(1):156-63.

8. Nambi V, Pedroza C, Kao LS. Carotid intima-media thickness and cardiovascular events. Lancet. 2012;379(9831):2028-30.

9. Polak JF, Pencina MJ, Pencina KM, O'Donnell CJ, Wolf PA, D'Agostino RB Sr. Carotid-wall intima-media thickness and cardiovascular events. N Engl J Med. 2011;365(3):213-21

10. Lorenz MW, von Kegler S, Steinmetz H, Markus HS, Sitzer M. Carotid intimamedia thickening indicates a higher vascular risk across a wide age range: prospective data from the carotid atherosclerosis progression study (CAPS). Stroke. 2006;37(1):87-92.

11. WG MA, Zheng J, Liu YM, Zhu JM, Sun LZ. Dr. Sun's procedure for type a aortic dissection: Total arch replacement using Tetrafurcate graft with stented elephant trunk implantation. Aorta. 2013;1 (1):59-64.

12. Mancia G, Fagard R, Narkiewicz K, Redon J, Zanchetti A, Bohm M, Christiaens T, Cifkova R, De Backer G, Dominiczak A, et al. 2013 ESH/ESC guidelines for the management of arterial hypertension: the task force for the Management of Arterial Hypertension of the European Society of Hypertension (ESH) and of the European Society of Cardiology (ESC). Eur Heart J. 2013;34(28):2159-219.

13. Kernan WN, Viscoli CM, Brass LM, Broderick JP, Brott T, Feldmann E, Morgenstern LB, Wilterdink JL, Horwitz R. Phenylpropanolamine and the risk of hemorrhagic stroke. N Engl J Med. 2000;343(25):1826-32.

14. Livesay JJ, Cooley DA, Duncan JM, Ott DA, Walker WE, Reul GJ. Open aortic anastomosis: improved results in the treatment of aneurysms of the aortic arch. Circulation. 1982;66(2 Pt 2):1122-7.

15. Lansman SL, Raissi S, Ergin MA, Griepp RB. Urgent operation for acute transverse aortic arch dissection. J Thorac Cardiovasc Surg. 1989;97(3): 334-41.

16. Di Eusanio M, Trimarchi S, Patel HJ, Hutchison S, Suzuki T, Peterson MD, Di Bartolomeo R, Folesani G, Pyeritz RE, Braverman AC, et al. Clinical presentation, management, and short-term outcome of patients with type a acute dissection complicated by mesenteric malperfusion: observations from the international registry of acute aortic dissection. J Thorac Cardiovasc Surg. 2013;145(2):385-90 e381.

17. Nambi V, Chambless L, Folsom AR, He M, Hu Y, Mosley T, Volcik K, Boerwinkle E, Ballantyne CM. Carotid intima-media thickness and presence or absence of plaque improves prediction of coronary heart disease risk: the ARIC (atherosclerosis risk in communities) study. J Am Coll Cardiol. 2010; 55(15):1600-7.

18. O'Leary DH, Polak JF, Kronmal RA, Manolio TA, Burke GL, Wolfson SK Jr. Carotid-artery intima and media thickness as a risk factor for myocardial infarction and stroke in older adults. Cardiovascular health study collaborative research group. N Engl J Med. 1999:340(1):14-22.

19. Bots ML, Hoes AW, Koudstaal PJ, Hofman A, Grobbee DE. Common carotid intima-media thickness and risk of stroke and myocardial infarction: the Rotterdam study. Circulation. 1997;96(5):1432-7.

20. Sehestedt T, Jeppesen J, Hansen TW, Wachtell K, Ibsen H, Torp-Pedersen C, Hildebrandt $\mathrm{P}$, Olsen $\mathrm{MH}$. Risk prediction is improved by adding markers of subclinical organ damage to SCORE. Eur Heart J. 2010;31(7):883-91.

21. Greenland P, Alpert JS, Beller GA, Benjamin EJ, Budoff MJ, Fayad ZA, Foster E, Hlatky MA, Hodgson JM, Kushner FG, et al. 2010 ACCF/AHA guideline for assessment of cardiovascular risk in asymptomatic adults: executive summary: a report of the American College of Cardiology Foundation/ American Heart Association task force on practice guidelines. Circulation. 2010;122(25):2748-64.

22. Di Eusanio M, Berretta P, Cefarelli M, Castrovinci S, Folesani G, Alfonsi J, Pantaleo A, Murana G, Di Bartolomeo R. Long-term outcomes after aortic arch surgery: results of a study involving 623 patients. Eur I Cardiothorac Surg. 2015;48(3):483-90.

23. Ehrlich MP, Ergin MA, McCullough JN, Lansman SL, Galla JD, Bodian CA, Apaydin AZ, Griepp RB. Predictors of adverse outcome and transient neurological dysfunction after ascending aorta/hemiarch replacement. Ann Thorac Surg. 2000;69(6):1755-63.

24. Liu H, Chang Q, Zhang H, Yu C. Predictors of adverse outcome and transient neurological dysfunction following aortic arch replacement in 626 consecutive patients in China. Heart Lung Circ. 2017;26(2):172-8.

25. Ehrlich MP, Schillinger M, Grabenwoger M, Kocher A, Tschernko EM, Simon P, Bohdjalian A, Wolner E. Predictors of adverse outcome and transient neurological dysfunction following surgical treatment of acute type a dissections. Circulation. 2003;108(Suppl 1):|1318-23.

\section{Publisher's Note}

Springer Nature remains neutral with regard to jurisdictional claims in published maps and institutional affiliations.

Ready to submit your research? Choose BMC and benefit from:

- fast, convenient online submission

- thorough peer review by experienced researchers in your field

- rapid publication on acceptance

- support for research data, including large and complex data types

- gold Open Access which fosters wider collaboration and increased citations

- maximum visibility for your research: over $100 \mathrm{M}$ website views per year

At $\mathrm{BMC}$, research is always in progress.

Learn more biomedcentral.com/submission 